\title{
O efeito de um filme de abuso sexual no comportamento agressivo das adolescentes
}

\author{
Paula Inez Cunha Gomide ${ }^{1}$ \\ Andressa Sperancetta \\ Universidade Federal do Paraná
}

\begin{abstract}
Resumo
Este estudo analisou a influência de um filme de abuso sexual em comportamento agressivo de adolescentes do sexo feminino. O fenômeno é explicado principalmente pelas teorias de Bandura (1986), Zillmann (1971), Huesmann (1982) e de Berkowitz (1984, 1988). Também a etologia analisa a raiva como um mecanismo que antecede e pode desencadear tal comportamento. A amostra foi constituída por 82 adolescentes do sexo feminino. Comparando-se o comportamento agressivo em pré e pós-teste obteve-se um $t(82)=3,93 ; p<.0001$; e média de $3,18(s=2,85)$ para o pré-teste e de 5,07 $(s=4,24)$ para o pós-teste; mostrando uma maior variabilidade de respostas no pós-teste. Estes resultados, à luz da etologia - onde uma estimulação violenta desencadeia raiva, e esta emoção desencadeia o comportamento agressivo - sugerem, que assistir a filmes com, conteúdo violento de abuso sexual pode ser mais um fator que contribui para o aumento da agressividade humana.
\end{abstract}

Palavras-chave: comportamento agressivo; filme violento; adolescentes do sexo feminino, etologia, raiva.

\begin{abstract}
The effect of a sexual abuse movie on a adolescents aggressive behavior

This study analyzed the influence of a sexual abuse movie on female adolescent aggressive behavior. The main theories about this subject spring from Bandura (1986), Zillmann (1971), Huesmann (1982) and Berkowitz $(1984,1988)$. The ethological perspective also analyzes anger as precedent to aggressive behavior and as one of the mechanisms that are able to stimulate aggressive behavior through midia violence. The sample was composed of 82 female adolescents. By comparing the scores on aggressive behavior in pre and post-test the results were $\mathrm{t}(82)=3,93 ; \mathrm{p}<.0001 ; \mathrm{x}=3,18(s=$ $2,85)$ for pre-test and $\mathrm{x}=5,07(s=4,24)$ for the post-test, with more variability in the post-test response. This result, from the ethological point of view - where a violent stimulation elicits anger and this anger elicits aggressive behavior - proposes that watching a violent sexual abuse film may be one of the factors that contribute to the enhancement of human aggressiveness.

Keywords: aggressive behavior; violent movies; female adolescent; ethology, anger.
\end{abstract}

As dimensões e os parâmetros dos processos de socialização que levam às diferentes formas de expressão de comportamento agressivo, assim como os processos psicológicos envolvidos na socialização dos indivíduos, são questões fundamentais para o entendimento dos efeitos a longo prazo da exposição à violência na mídia. Muitos pesquisadores têm elaborado teorias que relacionam a exposição a determinados tipos de estimulação na infância com o aprendizado e manutenção de hábitos agressivos. As mais influentes têm sido a Teoria da Aprendizagem Social de Bandura (1986), a Teoria da Transferência da Estimulação e Excitação de Zillmann (1971) a Teoria da Aprendizagem Observacional Cognitiva ou do Processamento de Informação de Huesmann (1982) e a Perspectiva Neo-associassionista de Berkowitz (1984, 1988).
Bandura e Walters (1963) desenvolveram a Teoria da Aprendizagem Social ou de Reforçamento Vicário, a qual propõe que crianças podem aprender comportamentos complexos observando um modelo e que esta aprendizagem é altamente resistente à extinção. Zillmann (1971) desenvolveu a Teoria da Transferência da Estimulação e Excitação, argumentando que a excitação aumenta a propensão da pessoa vir a se comportar agressivamente e, a violência na televisão, aumenta e perpetua esta estimulação. O terceiro autor, Huesmann (1982), argumentou que as crianças não só aprendem comportamentos, mas também atitudes, valores e crenças, e denominou sua teoria de Aprendizagem Observacional Cognitiva, acrescentando que pessoas agressivas gostam de ver violência na mídia porque isto poderá justificar seus próprios atos, visto que a violência exibida na televisão e em filmes raramente é 
punida, ou, então, quando a punição ocorre, ela está muito distante do ato agressivo. Berkowitz (1984) propõe a Teoria Cognitiva Neo-associativa ou Teoria das Pistas Cognitivas para explicar como hábitos agressivos aprendidos no passado podem ser desencadeados por exposição a cenas violentas.

Ademais, dentre os mecanismos através dos quais a violência na mídia estimula diretamente o comportamento agressivo, tem-se considerado a raiva como uma emoção que antecede e pode desencadear tal comportamento; estas explicações são sustentadas pela etologia.

\section{A Teoria da Aprendizagem Social}

Já que para Bandura e Iñesta (1975) a aprendizagem social exerce um papel fundamental na aquisição de respostas agressivas - distinguindo a aquisição de respostas que são potencialmente destrutivas ou causam dor das condições que governam seu desempenho subseqüente -, destacamse os padrões de comportamento agressivo adquiridos sob condições não-frustradoras, como a ausência de intenção de dano e em relação a objetos inanimados. Exemplos disso são o aprendizado de habilidades combativas pelos militares por meio de tiro ao alvo e lutas simuladas, e o treino dos boxeadores em sacos de areia. Nesse sentido, o autor afirma que se os repertórios agressivos só fossem ensinados enquanto os indivíduos estivessem sob o efeito de sentimentos hostis e procurassem provocar lesões, muitos dos comportamentos envolvidos na fase de aquisição seriam desfigurados.

Bandura e Iñesta (1975) consideram ainda que, após a aprendizagem de padrões agressivos por observação de modelos agressivos, estes podem ser mantidos por uma grande variedade de reforçadores. De acordo com as teorias que postulam a existência de impulsos agressivos, como a de Feshbach (1956), as pistas de dor e outras conseqüências injuriosas vivenciadas pela vítima constituem os principais reforçadores do comportamento agressivo ou recompensa para o agressor. Por outro lado, Bandura (1979) salienta que a agressão aparece mais frequientemente por possuir elevado valor utilitário e não tanto em função da dor da vítima. A agressão torna-se utilitária visto que a dominância da força verbal e física proporciona a obtenção de recursos materiais, mudança de regras, controle e subserviência dos outros, e remoção de barreiras que bloqueiam ou atrasam a consecução de resultados desejados. Além disso, as conseqüências sociais positivas da agressão fortalecem e mantêm o comportamento agressivo, como ocorre em meios (grupo familiar ou de pares) nos quais a agressão física é vista como um comportamento a imitar, ou é recompensada e aceita.

As teorias dos "impulsos" agressivos, afirma Bandura (1979), concebem a frustração como desencadeadora de impulso agressivo ou "drive", que só será reduzido por alguma forma de comportamento agressivo. Contrariando tais idéias, a perspectiva da aprendizagem social de Bandura vê a frustração como facilitadora da agressão e não como uma condição necessária. Em outras palavras, “(...) a frustração produz um estado geral de intensificação emocional que pode conduzir a uma variedade de respostas, que dependem do tipo de reação à frustração que foram previamente aprendidos e das conseqüências reforçadoras tipicamente associadas com linhas diferentes de ação" (Bandura, 1979, p. 225).

\section{A teoria da Transferência da Estimulação e da Excitação}

Outros autores, em contrapartida, têm sustentado que a estimulação aumenta a possibilidade de a pessoa se comportar agressivamente, e a violência exibida na televisão aumenta ou perpetua esta estimulação. Estudos de Geen (1983) e Zillmann (1971) demonstraram que, aumentando a excitação geral do sujeito, eleva-se a probabilidade da ocorrência de um comportamento agressivo. Em um experimento típico desta área de estudos, um sujeito engaja-se em uma atividade física que aumenta sua taxa de batimento cardíaco e então é testada a sua tendência para responder agressivamente à provocação (Zillmann, Katcher e Milavsky, 1972).

A teoria da transferência de excitação também tem sido usada para explicar como a pornografia nãoviolenta poderia estimular o comportamento agressivo. Zillmann (1978, 1983) e Zillmann e Bryant (1984) observam que a estimulação fisiológica produzida por um estímulo sexual ou outro estímulo qualquer pode influenciar o comportamento agressivo em uma outra situação temporalmente próxima. É sustentado que, quando a excitação decorre de mais de uma fonte de estímulos, o indivíduo é incapaz de distinguir entre a excitação produzida por cada fonte. Excitações de múltiplas fontes são entendidas como sendo aditivas, de modo que o estímulo sexual provocador, por exemplo, possa ter um efeito de intensificar a raiva. Provavelmente, pessoas em altos níveis de estimulação respondem mais fortemente e impulsivamente ao estímulo provocador e, portanto, serão mais agressivas devido a esta excitação "transferida". A duração de cada excitação é relativamente curta (isto é, indetectável depois de poucas horas); assim, esta teoria não pode ser usada para explicar efeitos prolongados da violência na 
mídia.

Em recente experimento, Zillmann e Weaver (1999) expuseram os participantes a filmes contendo violência gratuita e a filmes não violentos, por quatro dias consecutivos. Em seguida, avaliaram o valor de entretenimento desses filmes. Um dia depois da exposição ao último filme da série, os sujeitos participaram de uma ostensiva e privativa pesquisa sobre reconhecimento de emoções. Então, foram tratados de forma neutra ou abusiva por um assistente de pesquisa e em seguida lhes foi permitido prejudicar ou fazer bem a esse assistente. Tanto a provocação quanto a exposição aos filmes violentos foram bases para promover um aumento acentuado de comportamento hostil. Além disso, tais efeitos foram uniformes quanto ao gênero dos participantes. Comparadas aos homens, as mulheres exibiram menos hostilidade global. Os autores concluíram, então, que a exposição prolongada a filmes de violência gratuita é capaz de intensificar o comportamento hostil de homens e mulheres provocados e, talvez mais significativamente, estimular tal comportamento em homens e mulheres que não foram provocados.

Zillmann (1971) acredita que, quando existe uma seqüência de provocações, cada uma dispara uma reação excitatória que demora a se dissipar; cada pensamento ou percepção torna-se um gatilho de surtos de catecolaminas, os quais se alimentam do impulso hormonal do anterior. Cada onda vem na esteira das anteriores, elevando rapidamente o nível de estimulação fisiológica. Um pensamento que ocorra depois desse acúmulo provoca uma intensidade de raiva muito maior que um pensamento que o anteceda. Para o autor, tal estado pode promover uma sensação de poder que inspira e facilita a agressão. Avaliar e contestar as idéias que disparam o surto pode ser eficiente para interromper a raiva; porém, isso funciona melhor em níveis moderados de raiva. Em níveis altos, não faz diferença, por causa do que o autor chama de "incapacitação cognitiva", impossibilitando o indivíduo de pensar direito. Por exemplo, numa discussão, afastar-se da outra pessoa, no exato momento em que surge a raiva, pode ser a solução; outra alternativa é a distração (caminhar, relaxar, ouvir música ou ler), para que se interrompa a cadeia de raiva. Tice e Baumeister (1993) constataram que dar vazão à raiva não é a melhor forma de eliminá-la. Os que assim agiram, descontando sua raiva na pessoa que os provocara, continuavam a sentir raiva; tal mecanismo mostrou-se muito mais efetivo quando as pessoas primeiro "esfriavam" e depois, de uma maneira construtiva ou assertiva, enfrentavam a outra.

Zillmann (1993) realizou ainda um experimento em que um de seus auxiliares provocava, por meio de observações sarcásticas, os homens e mulheres participantes. Em seguida os participantes assistiam a dois gêneros de filme, um agradável e outro desagradável. Logo após, eram convidados a fazer uma avaliação que, julgavam, pesaria na decisão de contratar ou não o auxiliar. A intensidade do revide era diretamente proporcional ao estímulo que recebiam do filme a que assistiram: os que assistiam ao filme desagradável eram os mais furiosos e faziam as piores avaliações do candidato ao emprego.

Outro experimento, relacionado com as teorias da estimulação, foi conduzido por Calvert e Tan (1994), citado em Zilmann (1999). Examinou-se o impacto da participação ou da observação de atos agressivos representados em jogo de realidade virtual (VRG) sobre os níveis de estimulação, sentimentos de hostilidade e pensamentos agressivos de 36 adultos jovens. A hipótese era que a excitação fisiológica e pensamentos agressivos aumentariam mais naqueles que participaram diretamente do VRG do que entre aqueles que observaram. Os sujeitos que jogaram VRG agressivo exibiram excitação fisiológica elevada e aumento de pensamentos agressivos maiores que os que só observaram o jogo ou que simularam movimentos do VRG. Elevações das taxas cardíacas foram consideradas pelos autores como suporte para a teoria da estimulação, e aumentos de pensamentos agressivos forneceram subsídios para a teoria cognitivo-social. No entanto, verificou-se que a condição de observador não produziu mais agressão, como tem sido prognosticado pela teoria cognitivosocial.

Zillmann (1983) apresentou também evidências acerca do processo de empatia característico da observação do estado emocional do protagonista de um filme. $\mathrm{O}$ autor salientou que a reação emocional do observador pode ser produzida por algum aspecto da situação que não seja somente a resposta emocional presenciada per se. Além disso, a resposta emocional do observador pode ou não se assemelhar à do ator.

Segundo Bandura (1979), a empatia é um fenômeno aprendido que pode se desenvolver pelo condicionamento clássico. Nesse sentido, as expressões afetivas de outras pessoas são freqüentemente seguidas de conseqüências emocionais similares no observador e, assim, tornamse estímulos condicionados. Já para Zillmann (1983), o comportamento do protagonista interfere nas respostas emocionais do telespectador. As pessoas parecem experimentar emoções que correspondem às do protagonista quando este é benquisto - ou comporta-se de forma benevolente -, e emoções discordantes quando é visto com ressentimento. 


\section{Teoria da Aprendizagem Observacional Cognitiva}

A agressão humana é estudada, atualmente, como um produto da interação de vários fatores, tais como genéticos, perinatais, fisiológicos, familiares e de aprendizagem. $\mathrm{Na}$ realidade, sugere-se que o comportamento agressivo e anti-social mais grave ocorre somente quando alguns desses fatores convergem (Huesmann, 1986). Outra evidência salienta que o comportamento agressivo habitual emerge muito cedo, e é um sinal de agressividade futura. A partir dessa perspectiva, o comportamento agressivo nas crianças tende a aumentar na adolescência. As crianças mais agressivas tornam-se os adultos mais agressivos, afirma o autor.

As pesquisas de Bandura (1973), Berkowitz (1984), Eron, Walder e Berkowitz (1971) e Huesmann (1982) concluíram que, apesar de os fatores genéticos e fisiológicos exercerem influência sobre a agressividade de algumas crianças, é a maior parte das primeiras experiências das crianças que as moldam em jovens mais ou menos agressivos. Assim, as interações com o meio servem como aprendizagem de padrões comportamentais, facilitando ou não o desenvolvimento da agressividade. Um ambiente repleto de privações, frustrações e provocações frequientemente estimula agressão. Além disso, as principais condições para a aprendizagem da agressão por parte da criança são: muitas oportunidades de observar agressão, o reforço proveniente do próprio comportamento agressivo, assim como ser ela o objeto da agressão (Huesmann, 1986).

Huesmann, Moise e Podolski (1997) destacam que os elementos do ambiente mais importantes teoricamente na determinação de diferenças individuais de respostas para privação, frustração e provocação são a família da criança, os pares (os companheiros) e o contexto cultural, o qual inclui a mídia.

As diferenças que predispõem à impulsividade e à irritabilidade, por exemplo, podem ser moderadas ou exacerbadas pelas experiências prematuras de aprendizagem das crianças; mas, uma vez estabelecido um padrão habitual de comportamento, torna-se muito difícil mudá-lo.

A perspectiva do processamento de informação de Huesmann (1986) postula que um comportamento social, como a agressão, é controlado por uma grande extensão de "programas" ou scripts cognitivos que foram aprendidos durante o desenvolvimento. Eles são armazenados na memória e podem ser recuperados para guiar comportamentos. Em relação ao comportamento agressivo, o autor assinala que: “(..) uma criança habitualmente agressiva é aquela que regularmente recupera e emprega scripts para comportamentos sociais que enfatizam respostas agressivas" (Huesmann, 1986, p. 131). Tais respostas, por sua vez, se são reforçadas, fazem que estes scripts sejam mais prováveis de serem recuperados no futuro. A exposição à violência contribui para esse processo, no sentido de desenvolver e manter scripts cognitivos que enfatizam soluções agressivas para problemas sociais. A percepção de que uma cena agressiva é real e a identificação com o ator são fatores que favorecem o seu efeito sobre a cognição infantil.

Em contrapartida, a maioria dos estudos sobre a relação entre a exposição à violência na mídia especificamente na televisão e em filmes - e comportamento violento já demonstraram que crianças, adolescentes e adultos que assistem a mais violência comportam-se mais violentamente e expressam opiniões mais tolerantes ao comportamento agressivo, por meio do processo de dessensibilização, bem como podem ficar com mais medo perante o mundo real (Huesmann e cols., 1997; Geen, 1983, 1990; Bandura, 1963; Malamuth e Donnerstein, 1982; Strasburger, 1999).

Wartella, Olivarez e Jennings (1999), analisando os comportamentos violentos que têm lugar na sociedade norte-americana, ressaltam que ignorá-los na televisão seria um grave descuido ao se estudar os vários fatores que contribuem para a violência na sociedade. Afirmam que através da televisão, pode-se assistir à violência em videoclipes, shows de entretenimento, documentários e noticiários, sem contar os filmes. Huston e cols. (1992) demonstraram que, ao terminar o primeiro grau, uma criança norteamericana comum terá visto mais de oito mil assassinatos e mais de 100 mil outros atos de violência na TV. As mesmas autoras apresentam três análises de literatura realizadas nos EUA na década de 1990 sobre os efeitos da violência na televisão: o relatório de 1991 dos centros para controle de doenças, que declarou que a violência na televisão é um mal para a saúde pública; o estudo da academia nacional de ciências, que, em 1993, relacionou a mídia, juntamente com outros fatores sociais e psicológicos, como um fator que contribui para a violência; e o estudo da Associação de Psicologia Americana (APA), de 1992, que também denunciou a violência na mídia.

\section{A Teoria Cognitiva Neo-associativa}

Enquanto os processos de aprendizagem observacional explicam como a exposição à violência da mídia pode ensinar hábitos agressivos, a teoria do "priming" (da prontidão) de Berkowitz (1984) dá interessantes explicações sobre como hábitos 
aprendidos através de outras vias podem ser desencadeados por exposições à violência na mídia. $\mathrm{O}$ autor propôs que "a idéia agressiva sugerida por um filme violento pode 'preparar' outros pensamentos semanticamente relacionados, aumentando as chances de que os telespectadores possam ter outras idéias agressivas neste período" (Berkowitz, 1984, p. 411). Nesse sentido, assistindo a um ato agressivo na televisão, o indivíduo tem ativados pensamentos, emoções e até comportamentos cognitivamente associados. Tal posição é útil na explicação de por quê a observação da agressão na mídia é freqüentemente seguida de atos agressivos diferentes do comportamento observado. Um estudo de Leyens e Parke (1975) identificou que sujeitos que haviam visto slides de armas estavam mais dispostos a punir severamente um alvo que os sujeitos que tinham visto slides neutros. Presumivelmente, ver as armas estimulou outras idéias agressivas e emoções, afetando então as atitudes subseqüientes dos telespectadores.

Uma visão relacionada focaliza a importância das pistas no processo de relembrar a agressão aprendida através da observação. A idéia das pistas é que no tempo da observação do telespectador surgem ambas: a agressividade do ato e qualquer outra informação relevante que porventura esteja no meio ambiente (um objeto particular, por exemplo) e que mais tarde poderá servir como pista de recordação. Um estudo que demonstrou este efeito foi realizado por Josephson's (1987) com jogadores de hockey. Os garotos foram frustrados deliberadamente e, em seguida, um grupo assistiu a um programa violento e outro a um não-violento. De fato, durante o jogo subseqüente os garotos mais agressivos foram os que haviam visto o programa violento.

Berkowitz (conforme citado por Johnson, 1979) observa que, às vezes, o comportamento agressivo representa uma resposta condicionada a estímulos situacionais, sobretudo quando pistas ambientais se combinam com estados de excitação interna, como a raiva, para produzir reações impulsivas agressivas. Ilustrando esse efeito, pode-se mencionar o experimento de Berkowitz e LePage (1967). Os sujeitos foram instruídos a desempenhar o papel de um experimentador tentando ensinar uma tarefa aos outros. Quando os sujeitos cometiam erros, o experimentador (no caso um dos sujeitos) aplicava um castigo sob a forma de choques elétricos. No grupo experimental, um revólver foi colocado sobre uma mesa próxima ao sujeito e no grupo controle esta arma estava ausente. A arma servia como uma pista situacional e verificou-se que os experimentadores castigavam seus sujeitos mais severamente através dos choques quando a arma estava presente em comparação com a situação em que ela estava ausente. Desse modo, percebeu-se que a arma facilitou o comportamento agressivo devido à sua associação com a violência e o derramamento de sangue.

Por outro lado, nem sempre os estímulos eliciadores da agressão precisam ter associações prévias bem estabelecidas, pois tais associações podem ser adquiridas rapidamente. Esse fato foi demonstrado por Berkowitz e Geen (1966), que vincularam o nome de um estranho a um personagem repugnante do cinema. Na primeira etapa desse experimento, um cúmplice agia como experimentador e avaliava o desempenho dos seus sujeitos aplicandolhes choques elétricos por um trabalho inadequado. Depois, alguns sujeitos viram cenas do filme Campeão, no qual Kirk Douglas é derrotado numa luta de boxe. Por sua vez, os sujeitos de controle viram um filme neutro. Após a exibição dos filmes, os sujeitos desempenharam o papel do experimentador que aplicava os choques. Cada grupo foi novamente subdividido: para a metade dos sujeitos, o cúmplice recebia o nome de "Bob" e para os demais, seu nome era "Kirk". Os resultados mostraram que os sujeitos que haviam sido enraivecidos por receberem choques na primeira parte do experimento e que tinham visto o filme de boxe eram significativamente mais punitivos em relação aos cúmplices chamados "Kirk" do que aos chamados "Bob". Os autores concluíram que o comportamento agressivo foi incrementado pelos seguintes fatores: raiva prévia, observação da agressão e associação do cúmplice com a pessoa do filme.

Berkowitz (conforme citado por Johnson, 1979) argumenta que em certas situações os estímulos ambientais associados com as reações agressivas intensificam as reações previamente já "armazenadas" mas não desencadeadas, ou seja, uma pessoa previamente zangada por um motivo que não desencadeou o comportamento agressivo, terá uma resposta de raiva diante de um outro estimulo eliciador, aparentemente não suficiente ou relacionado ao comportamento de raiva. Certamente, diz Johnson (1979), os estímulos situacionais e os fatores emocionais são importantes, uma vez que os estudos demonstram que vários ataques violentos são provocados pela vítima (Wolfgang, 1957), e os conflitos com a lei são muitas vezes precipitados pelo comportamento da polícia (Toch, 1969). Entretanto, como assinala Kaufmann (1970), um indivíduo pode estar fervendo de raiva e não revelar nenhum comportamento anti-social e, por outro lado, atrocidades têm sido cometidas com pouco ou nenhum envolvimento emocional. A importância da raiva é que ela pode ter propriedades que intensificam 
o comportamento agressivo; contudo, não se deve admitir que a raiva é o desencadeante exclusivo da agressividade (Buss, 1961).

\section{Teoria etológica: a emoção da raiva que antecede o comportamento agressivo}

Os efeitos da televisão e de filmes violentos sobre as respostas afetivas que são mediadoras da agressão também têm sido claramente demonstrados. Por exemplo, Bushman e Geen (1990) indicaram que videotapes violentos eliciam tanto pensamentos agressivos quanto alta pressão sangüínea em estudantes universitários.

Dentre os mecanismos através dos quais a violência na mídia estimula diretamente comportamento agressivo, tem-se considerado a raiva como uma emoção que antecede e pode desencadear tal comportamento. Goleman (1995) caracteriza a raiva como uma reação acompanhada de pressão sangüínea aumentada, batimentos cardíacos acelerados, sudorese e uma ação de hormônios, como a adrenalina, que impulsionam para uma atuação vigorosa.

Para Zilmann (1993), o disparador universal da raiva é a sensação de estar em perigo, que pode ser sinalizada não apenas por uma ameaça física direta, mas também, como é mais freqüente, por uma ameaça simbólica à auto-estima ou à dignidade, representada por tratamento injusto ou grosseiro, insulto ou humilhação e frustração na busca de um objetivo, por exemplo. Essas percepções instigam uma onda límbica que tem um duplo efeito sobre o cérebro. Uma parte dessa onda é a liberação de catecolaminas, que geram um rápido surto de energia, suficiente para uma linha de ação vigorosa, como no lutar-ou-fugir. Enquanto isso, outra onda impulsionada pela amígdala - estrutura límbica responsável pela avaliação do significado emocional dos fatos, funcionando como um depósito da memória emocional - percorre o ramo adrenocortical do cérebro, criando um pano de fundo tônico de prontidão para a ação. Goleman (1995) afirma que esse estímulo adrenal e cortical generalizado pode durar horas e até mesmo dias, mantendo o cérebro em prontidão para o estímulo e tornando-se uma base sobre a qual reações posteriores se formam com rapidez. "Em geral, a condição de pronta resposta criada pela estimulação adrenocortical explica por que as pessoas são mais propensas à raiva quando já foram provocadas ou ligeiramente irritadas por alguma coisa" (Goleman, 1995, p. 73).

Ades (1996) destaca que, em função de as definições de emoção serem variadas entre as diversas abordagens da psicologia, o importante é entender os aspectos consensuais entre os estudiosos das emoções.
A experiência pessoal, tal como transparece em relatos verbais; as mudanças fisiológicas, que ativam o organismo e as formas através das quais as emoções se expressam, como a voz, os gestos, a face e a postura são consideradas características fundamentais das emoções pela maioria dos autores. Ades (1996) ainda menciona a relação existente entre a emoção e um evento ambiental ou a lembrança e a antecipação de um evento, como se este propiciasse o surgimento de um estado emocional. A experiência passada da pessoa e os indícios presentes são elementos que determinam como ela interpretará o evento ambiental. Portanto, o impacto de um evento depende das cognições do indivíduo.

Atualmente, aceitam-se, ao menos, dois papéis básicos da emoção: o ajustamento às pressões do ambiente, que tem função adaptativa e fornece julgamento das situações da vida, e a preparação para a ação, desempenhando também o papel de elemento de comunicação social (Ades, 1996). O autor apresenta as seguintes emoções como básicas para a espécie humana: alegria, surpresa, tristeza, raiva, nojo, desprezo, medo, vergonha e culpa. Considera, entretanto, que as emoções sempre ocorrem mescladas entre si.

\section{Reações das mulheres diante de representações sexualmente agressivas da mídia}

Os estudos de Bandura (1979) e Bandura e Iñesta (1975) não encontraram correlação positiva entre a apresentação de filmes violentos e comportamento agressivo em participantes do sexo feminino. A literatura explica que a história de socialização das mulheres não inclui comportamento de luta de tal forma que não há imitação de modelo nem tampouco identificação comportamental com o modelo agressivo de filmes de ação. No entanto, quando se apresenta a adolescentes do sexo feminino um filme com cenas de violência que incluem abuso físico e sexual, o resultado é um aumento estatisticamente significativo do comportamento agressivo (Gomide, 2000).

Em pesquisa anterior, Gomide (2000) encontrou um aumento do comportamento agressivo estatisticamente significativo em adolescentes do sexo feminino após a exposição a um filme (Kids) com violência sexual e física contra mulheres; porém não se observou aumento de comportamento agressivo das adolescentes quando assistiram a um filme violento com herói, resultado coerente com o modelo teórico de Bandura (1969). No entanto, a literatura não se refere à utilização de heroínas como modelos agressivos em filmes violentos. Esta poderia ser uma variável relevante, de tal modo que dois estudos foram 
realizados (Gomide, Ciscato e Araújo, 1997) com o objetivo de verificar o efeito de filmes violentos, com uma personagem heroína, sobre o comportamento de adolescentes do sexo feminino. Dois grupos de adolescentes foram organizados: um deles com 38 adolescentes que assistiram a um episódio do seriado "A Justiceira", e outro com 39, que viram um episódio de "Nikita", ambos transmitidos pelas emissoras de televisão brasileiras, cujas protagonistas eram heroínas que utilizavam armas e lutavam em defesa de "pessoas" ou "causas justas". Antes e depois do filme, as participantes jogaram futebol de salão, nos quais seus comportamentos agressivos foram registrados. As médias de pré-teste e pós-teste para os dois grupos foram comparadas pelo teste $t$ de Student, obtendo-se um $t=1,49(\mathrm{p}<0,145)$ para o grupo de adolescentes que assistiu A Justiceira e $t=-0,40(\mathrm{p}<0,694)$ para o grupo que viu Nikita. Tal resultado mostrou que as participantes comportaram-se de forma similar em pré e pós-testes. Neste caso, não se pôde apoiar, portanto, a hipótese de que as adolescentes pudessem se identificar com a heroína e imitar posteriormente seu comportamento agressivo.

Duas linhas de pesquisa, cada uma enfatizando um tipo diferente de resultados para mulheres que são expostas à violência pornográfica e sexual, têm emergido nos últimos anos (Linz e Malamuth, 1993).Uma delas tem utilizado homens e mulheres que são expostos à pornografia e variáveis dependentes que medem falta de interesse em valores familiares tradicionais, falta de respeito com a mulher e a punição de homens estupradores. A outra abordagem examina a análise feminina da pornografia, a qual enfatiza as ofensas que possam ocorrer contra a mulher como uma função da exposição de homens à pornografia e outros tipos violência sexual transmitidas pela mídia. No entanto, os efeitos da exposição às representações de dominância sobre mulheres telespectadoras, seus sentimentos de temor e reações à violência sexual ainda são largamente desconhecidos. Não são especificados claramente quais sintomas podem estar presentes após uma situação que coloca a mulher como vítima sexual; porém, algumas reações são encontradas entre as vítimas: uma sensação aumentada de vulnerabilidade para estupro ou outro crime; tolerância a comportamento sexualmente incômodo ou coerção sexual; tolerância para definições estereotipadas de papel sexual; auto-estima rebaixada e insatisfação com a imagem corporal depois da exposição à pornografia ou ao estupro (Baron, 1979; Jaffe, Malamuth, Feingold e Feshbach, 1974). Infelizmente, poucas pesquisas têm examinado o comportamento agressivo de mulheres após a exposição à pornografia. Esses estudos são limitados no que podem nos revelar a respeito do impacto geral da pornografia sobre as mulheres. Os efeitos da pornografia e outras cenas sexuais veiculadas pela mídia nas mulheres são, provavelmente, mais psicológicos que ligados ao comportamento antisocial, tal como a agressão aumentada.

Krafka, Linz, Donnerstein e Penrod (1997) estudaram universitárias que foram expostas a três tipos de filmes durante cinco dias: filme não violento com sexo explícito; filme com estímulo sexualmente violento e explícito; e segmentos de filmes que mostravam ataques violentos contra mulheres precedidos ou seguidos de cenas ligeiramente sexuais. $\mathrm{O}$ humor e as percepções sobre os filmes eram coletados diariamente. Assistir a estímulos agressivos e não agressivos sexualmente explícitos, ou imagens de violência contra mulheres em um contexto sexual mais leve foi uma experiência estressante para as mulheres neste estudo. A exposição resultou em aumento pronunciado de humor negativo para todos os grupos expostos.

\section{Objetivo da pesquisa}

Este estudo pretendeu analisar a influência de um filme que retrata episódios de abuso sexual em comportamento agressivo de adolescentes do sexo feminino.

\section{Método}

Participantes: A amostra foi constituída por 82 adolescentes do sexo feminino, com idades variando entre 12 e 18 anos, alunas do ensino fundamental e médio de escolas estaduais.

Filme utilizado: Marcas do Silêncio ${ }^{2}$ : A história se passa nas décadas de 50 e 60, em uma pequena cidade da Carolina do Sul (USA). Bone é uma menina de nove anos, filha de mãe solteira (Anne), que por não saber o nome do pai a registra somente com o nome da mãe. Anne pertencia a uma família simples, de muitos filhos; antes de engravidar morava com a mãe e seus irmãos. Casa-se com um rapaz que assume a paternidade de Bone; o casal tem uma filha; mas pouco tempo depois ele morre em um acidente de carro. Anne conhece o novo parceiro através de seus irmãos e vai morar com ele, pois não tem como sustentar duas filhas. Tem um filho do novo casamento que não sobrevive. Bone passa a conviver com o comportamento violento do padrasto, que a molesta física e sexualmente. Sofre espancamentos, estupros e também abusos psicológicos, como negligência e agressões verbais. A menina vive um 
longo período escondendo esse segredo, até que a família descobre tudo. Outro sofrimento se inicia quando sua mãe fica dividida entre a necessidade de um marido e a proteção da filha.

Medidas de agressividade: Foram registrados os seguintes comportamentos agressivos durante o jogo de futebol: a) Agarrar: segurar com uma ou ambas as mãos parte do corpo do adversário, impedindo o seu movimento; b) Chutar: bater com o pé no corpo do adversário, provocando o deslocamento do mesmo; c) Cotovelada: bater com um dos cotovelos no corpo do adversário, provocando o deslocamento do mesmo; d) Discutir: falar em qualquer tom de voz discordando ou reivindicando com seu companheiro, adversário, técnico ou juiz; e) Empurrar: deslocar o corpo do adversário utilizando-se da parte superior de seu corpo - mãos, braços e ombros; f) Puxar a camisa: pegar a camisa do adversário, provocando o deslocamento da camisa, impedindo ou não o movimento do adversário; g) Rasteira: colocar o pé ou perna junto ao corpo do adversário, provocando queda do mesmo ou perda do seu equilíbrio; h) Xingar: dizer palavrões, em qualquer tom, para uma pessoa ou sem sujeito definido.

Procedimentos: Os comportamentos agressivos das participantes foram medidos, em um jogo de futebol de salão, em pré e pós-teste. Entre os jogos as participantes assistiam ao filme "Marcas do Silêncio". Estas atividades ocorriam num mesmo dia, uma após a outra, em um tempo total de aproximadamente três horas. Foram formados 16 times, com cinco ou seis jogadores em cada um, e o tempo de jogo foi de quinze minutos (15'), tanto no pré-teste como no pósteste. As partidas foram filmadas para posterior registro dos comportamentos agressivos por uma dupla de observadores treinados. Cada participante teve seus comportamentos registrados em intervalos de dez segundos (10") durante todo o tempo de jogo. $\mathrm{O}$ índice de comportamento agressivo de cada participante foi obtido através da somatória de todos os comportamentos agressivos dividido por 90 (número de intervalos possíveis, ou seja, 15 vezes seis).

\section{Resultados}

Os dados foram analisados através do teste $t$ (de Student) e utilizou-se o índice de significância de 0.05. Comparando-se o comportamento agressivo das 82 participantes em pré e pós-teste obteve-se um t $(82)=3,93 ; \mathrm{p}<.0001$. As médias foram de 3,18 $(s=$ $2,85)$ para o pré-teste e de $5,07(s=4,24)$ para o pósteste; mostrando uma maior variabilidade de respostas no pós-teste. A figura 1 compara os índices de comportamento agressivo de cada participante, em jogo de futebol, antes e após assistirem ao filme "Marcas do Silêncio". É facilmente observável que a linha do pós-teste apresenta índices de comportamentos agressivos bem mais elevados que as do pré-teste. Em pré-teste apenas duas participantes, números 33 e 62, apresentaram índices maiores que $10 \%$ (11,6 e 13,3 respectivamente); já no pós-teste observa-se que oito participantes atingiram índices maiores que $10 \%$, as de número $12(10,41 \%), 19$ $(15,62 \%), 23(10,7 \%), 25(11,9 \%), 34(12,2 \%), 39$ $(17,7 \%), 46(17,9 \%)$ e $68(12,2 \%)$. 


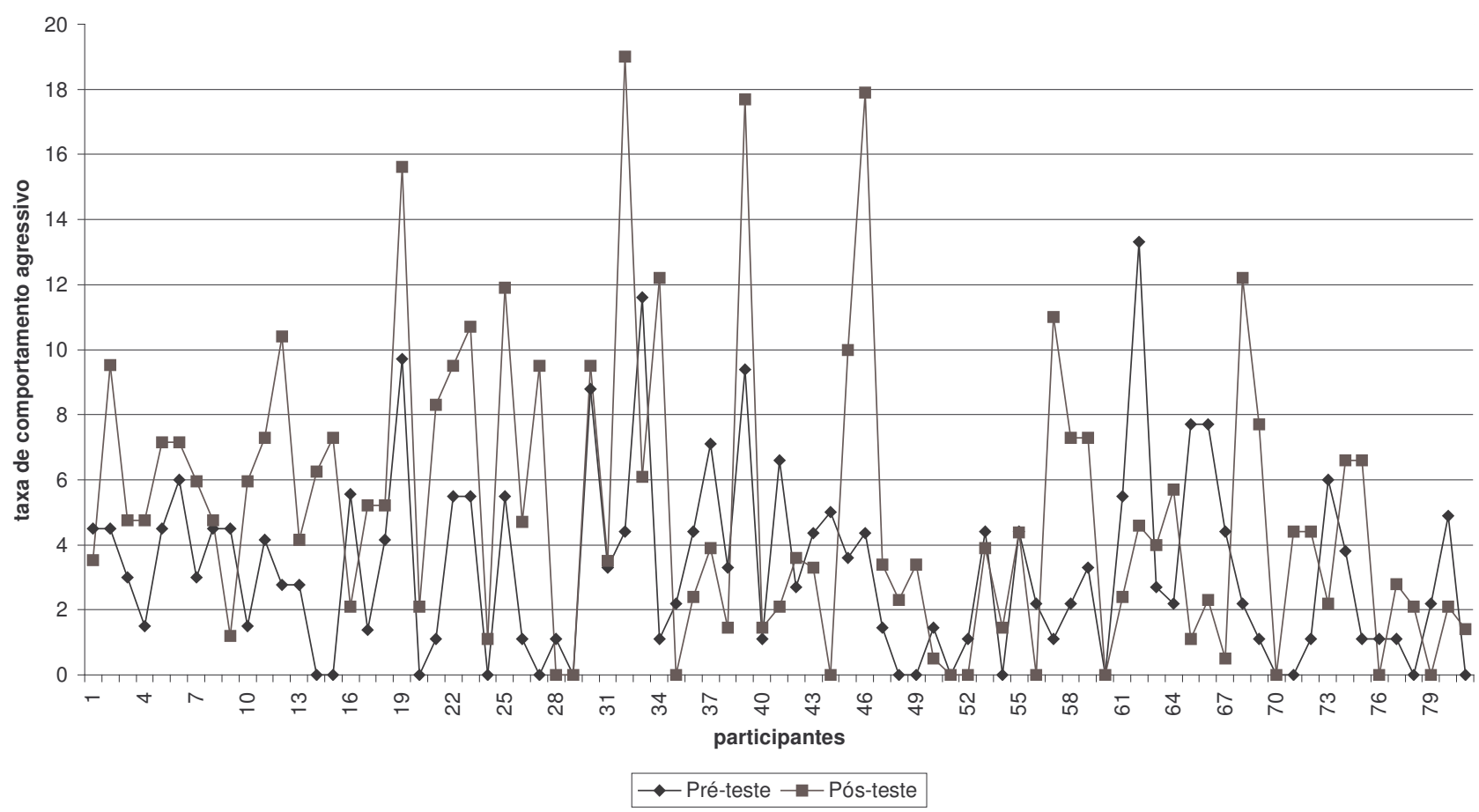

Figura 1. Comparação entre as taxas de comportamento agressivo, em jogo de futebol, antes e após assistirem ao filme "Marcas do Silêncio".

Observaram-se, durante a apresentação do filme, expressões agressivas contra o estuprador e muita agitação das participantes, que também vibraram quando os tios da menina violentada deram uma surra no estuprador, gritando e levantando-se das cadeiras. Estas observações, apesar de não terem sido sistematicamente registradas, apóiam a hipótese do aparecimento da raiva, pois são comportamentos que ocorrem simultaneamente a esta emoção.

\section{Discussão}

Tanto Bandura (1963), com a Teoria da Aprendizagem Social, que propõe que crianças podem aprender comportamentos complexos observando um modelo, como Huesmann (1982), com a Teoria de Aprendizagem Observacional Cognitiva, que argumentou que crianças não só aprendem comportamentos, mas também atitudes, valores e crenças, ambos estão lidando com comportamentos (observados ou encobertos) aprendidos pela observação de um modelo. Tais teorias não explicam os resultados desta pesquisas.

A Teoria da Transferência da Estimulação e Excitação de Zillmann (1971), que argumenta que a excitação aumenta a propensão de a pessoa vir a se comportar agressivamente, e a violência na televisão aumenta e perpetua esta estimulação, e a Teoria Cognitiva Neoassociativa ou a Teoria das Pistas Cognitivas de Berkowitz (1984), que propõem que hábitos agressivos aprendidos no passado podem ser desencadeados por exposição a cenas violentas, poderiam ser teorias explicativas deste fenômeno. No entanto, tais teorias requerem a utilização de um complexo construto teórico que pressupõe elementos cognitivos subjacentes responsáveis pelo desencadeamento de tais reações agressivas.

Interpretar estes resultados à luz da etologia - onde uma estimulação violenta desencadeia raiva, e esta emoção desencadeia o comportamento agressivo confere a análise dos dados um caráter mais parcimonioso. O comportamento agressivo é fruto de uma multivariedade de eventos (Gomide, 1996), que aparecem em função da proteção da prole, do território, do alimento - aspectos básicos da sobrevivência -, até aqueles desencadeados por frustração (Bandura, 1979), por modelos agressivos (Bandura, 1979) ou pela emoção da raiva (Johnson, 1979; Montagu, 1978; Ades, 1996).

A visão da agressão sofrida pela protagonista pode estar desencadeando a raiva. A agressão, humilhação, abuso sexual e ausência de proteção, enfim, todos estes fatores potencialmente poderiam estar correlacionados com a expressão da raiva.

Trilhando ainda os caminhos do modelo etológico, poder-se-ia sugerir que este "comportamento agressivo" que surge em jogo de futebol, após o filme de abuso sexual, teria a função de um comportamento deslocado; porém, neste caso, melhor adaptado. As 
manifestações de comportamento deslocado geralmente aparecem descontextualizadas, como no caso do primata jovem adulto que é empurrado pelo macho alfa e expõe o traseiro para o superior hierárquico ou agride um filhote alguns minutos depois (Johnson, 1979). Aqui, o comportamento agressivo, desencadeado pela emoção da raiva que surge em virtude da visão das cenas de abuso sexual vitimando uma menina apresentadas no filme, é redirecionado para uma situação onde a expressão da agressão, em um determinado nível, é aceita, ou é "politicamente correta".

O resultado deste estudo, estatisticamente significativo, com um índice de significância bastante confiável, sugere que, além das preocupações, já largamente demonstradas na revisão de literatura apresentada na introdução deste trabalho, pesquisadores e educadores devem investigar com maior profundidade os efeitos de filmes ou programas que desencadeiam a emoção da raiva ou por identificação ou porque estimulam recordações de cenas similares. A cadeia se retroalimenta: a mídia produz programas violentos porque pessoas assistem a programas violentos; pessoas que assistem a programas violentos têm maior probabilidade de se comportar agressivamente do que as que a eles não assistem; pessoas agressivas preferem assistir a programas com conteúdo agressivo; assistir a programas violentos aumenta a excitação geral do organismo, o que aumenta a sua potencialidade para ação e dá ao organismo uma sensação de bem-estar, de euforia, mantendo o comportamento de assistir a programas violentos. Estes resultados, à luz da etologia - onde uma estimulação violenta desencadeia raiva, e esta emoção desencadeia o comportamento agressivo -, sugerem que assistir a filmes com conteúdo violento de abuso sexual pode ser mais um fator que contribui para o aumento da agressividade humana.

\section{Referências}

Ades, C. (1996). De que trata a emoção. Torre de Babel: Reflexões e Pesquisa em Psicologia, 3, 7-26.

Bandura, A. \& Iñesta, E. R. (1975). Modificación de conductaAnálisis de agresión y la delicuencia. México: Editorial Trillas.

Bandura, A. \& Walters, R.H. (1963). Aprendizage social y desarrollo de la personalidad. Mexico City: Cidade Alianza.

Bandura, A. (1973). Aggression: a social learning analysis. Englewood Cliffs: Prentice Hall.

Bandura, A. (1979). Modificação do comportamento. Rio de Janeiro: Interamericana.

Bandura, A. (1986). Social foundations of thought and action: a social cognitive theory. Englewood Cliffs: Prentice Hall.

Baron, R.A. (1979). Heightened sexual arousal and physical aggression: An extension to females. Journal of Research in Personality, 13, 91-102.
Berkowitz, L. \& Geen, R.G. (1966). Film violence and the cue properties of available targets. Journal of Personality and Social Psychology, 3, 525-530.

Berkowitz, L. \& LePage, A. (1967). Weapons as aggressioneliciting stimuli. Journal of Personality and Social Psychology, 7, 202-207.

Berkowitz, L. (1984). Some effects of thoughts on anti- and prosocial influences of media events: a cognitiveneoassociation analysis. Psychological Bulletin, 95(3), 410427.

Berkowitz, L. (1988). Frustrations, appraisals and aversively stimulated aggression. Aggressive Behavior, 14, 3-12.

Bushman, B.J. \& Geen, R.G. (1990). Role of cognitive-emotional mediators and individual differences in the function of aggression and the regulation of aggressive drive. Psychological Review, 71, 257-272.

Buss, A. H. (1961). The Psychology of aggression. New York, Wiley.

Eron, L. D., Walder, L.O e Lefkowitz, M.M. (1971). Learning of aggression in children. Boston. M.A: Little, Brown e Co.

Feshbach, S. (1956) The Catharsis hypothesis and some consequences of interaction with aggressive and neutral play objects. J Pers., 24, 449-463.

Geen, R. G. (1983). Aggression and television violence. Em Geen, R.G. \& Donnerstein, E. (Orgs.), Aggression: Theoretical and empirical reviews, 2, 103-125. New York: Academic Press.

Geen, R. G. (1990). The influence of the mass media in human aggression. Pacific Grove: Brooks Cola.

Goleman, D. (1995). Inteligência emocional. (57 ed.) Rio de Janeiro: Objetiva.

Gomide, P.I.C. (1996). Agressão Humana. Torre de babel: Reflexões e Pesquisa em Psicologia, 3, 71-87.

Gomide, P.I.C. (2000). A influência de filmes violentos em comportamento agressivo de crianças e adolescentes. Psicologia: Reflexão e Crítica, 13(1), 127-141.

Gomide, P.I.C., Ciscato, M. \& Araújo, F. (1997). O efeito de filme violento com heroína em comportamento agressivo de adolescentes do sexo feminino. Relatório não publicado. PIBIC/ CNPq 1997/1998.

Huesmann, L.R. (1982). Television violence and aggressive behavior. Em D. Pearl, L. Bouthilet \& J. Lazar (Orgs.), Television and behavior: 10 years of programs and implications for the 80's (p. 126-137). Washington: Government Printing Office.

Huesmann, L.R. (1986). Psychological processes promoting the relation between exposure to media violence and aggressive behavior by the viewer. Journal of Social Issues, 42(3), 125139.

Huesmann, L.R.; Moise, J.F. \& Podolski, C.L. (1997). The effects of media violence on the development of antisocial bevavior. Em D.M. Stoff, J. Breiling, \& J.D. Maser (Orgs.), Handbook of antisocial behavior (p.). New York: John Wiley \& Sons, Inc.

Huston, A., Donnerstein, E., Fairchild, H., Feshbach, N., Katz, P., Murray, J., Rubinstein, E., Wilcox, B. \& Zuckerman, D. (1992). Big world, small screen: the role of television in american society. Lincoln: University of Nebraska Press.

Jaffe, Y., Malamuth, N., Feingold, J. \& Feshbach, S. (1974). Sexual arousal and behavioral aggression. Journal of Personality and Social Psychology, 30, 759-764.

Johnson, R.N. (1979). Agressão no homem e nos animais. Rio de Janeiro: Interamericana.

Josephson, W. L. (1987). Television violence and children's aggression: Testing the priming, social script, and disinhibition predictions. Journal of Personality and Social Psychology, 


$$
\text { 53(5), 882-890. }
$$

Kaufmann, H. (1970). Aggression and altruism. New York: Holt, Rinehart and Winston.

Krafka, C.; Linz, D.; Donnerstein, E. \& Penrod, S. (1997). Women's reactions to sexually aggressive mass media depictions. Violence against women, 3(2), 149-181.

Leyens, J. \& \& Parke, R.D. (1975). Aggressive slides can induce a weapons effect. European Journal of Social Psychology, 5(2), 229-236.

Linz, D. \& Malamuth, N.M. (1993). Communication concepts 5: Pornography. Newbury Park: Sage.

Malamuth, N.M. \& Donnerstein, E. (1982). The effects of aggressive-pornographic mass media stimuli. Em L. Berkowitz (Org.), Advances in experimental social psychology, 15, 103136. New York: Academic Press.

Montagu, A. (1978). A natureza da agressividade humana. Rio de Janeiro: Zahar Editores.

Strasburger, V. C. (1999). Os adolescentes e a mídia - Impacto psicológico. Porto Alegre: Artes Médicas.

Tice, D. \& Baumeister, R.F. (1993). Controlling anger: selfinduced emotion change. Em D. Wegner \& J. Pennebaker (Orgs.), Handbook of Mental Control, 5, Englewood Cliffs, N.J.: Prentice-Hall.

Toch, H. (1969). Violent Man. Chicago: Aldine.

Wartella, E., Olivarez, A. \& Jennings, N. (1999). A criança e a violência na televisão nos EUA. Em U. Carlson \& C. Von Feilitzen (Orgs.), A criança e a violência na mídia. São Paulo: Cortez.

Wolfgang, M.E. (1957). Victim-precipitated criminal homicide. Journal of Criminal Law, Criminology and Police Science, 48, $1-11$.

Zillmann, D. \& Bryant, J. (1984). Effects of massive exposure to pornography. Em Malamuth \& E. Donnerstein (Orgs.), Pornography and sexual aggression (p. 115-138). New York: Academic Press.

Zillmann, D. \& Weaver, J.B. (1999). Effects of prolonged exposure to gratuitous media violence on provoked and unprovoked hostile bevavior. Journal of Applied Social Psychology, 29(1), 145-165.

Zillmann, D. (1971). Excitation transfer in communicationmediated aggression behavior. Journal of Experimental Social Psychology, 7, 419-434.

Zillmann, D. (1978). Attribution and misattribution of excitatory reactions. Em J. H. Harvey, W.J. Ickes, \& R. F. Kidd (eds), New directions in attribution research, 2, 335-368. Hillsdale, NJ: Erlbaum.

Zillmann, D. (1983). Transfer of excitation im emotional behavior. Em J.T. Cacioppo \& R. E. Petty (eds), Social psychophysiology: A sourcebook (p. 215-240). New York: Guilford.

Zillmann, D. (1993). Mental control of angry aggression. Em Wegner \& J. Pennebaker (Orgs.), Handbook of Mental Control, 5. Englewood Cliffs: Prentice Hall.

Zillmann, D., Katcher, A. H. \& Milavsky, B. (1972). Excitation transfer from physical exercise to subsequent aggressive behavior. Journal of Experimental Social Psychology, 8, 247259.

Recebido: $14 / 06 / 2002$

Revisado: 20/06/2002 Aceito: 27/06/2002

\footnotetext{
Notas:

${ }^{1}$ Agradecimento: As autoras agradecem a participação especial para coleta e tabulação de dados do bolsista PIBIC-CNPq André del Olmo Sato.

${ }^{2}$ Título original "Bastard out of Carolina"; ano: 1996; USA; direção: Angélica Huston; distribuição no Brasil: Playarte.
}

Sobre as autoras

Paula Inez Cunha Gomide: Professora e pesquisadora do Programa de Pós-Graduação em Psicologia da Infância e da Adolescência da Universidade Federal do Paraná. Doutora em Psicologia Experimental pela Universidade de São Paulo. Endereço para correspondência: Universidade Federal do Paraná, Departamento de Psicologia, Praça da Ucrânia, 80, apto. 162, CEP 80730-430, Curitiba, Paraná. Fone: (41) 310-2644, E-mail: pgomide@ onda.com.br

Andressa Sperancetta: Aluna do curso de Psicologia da Universidade Federal do Paraná. Bolsista PIBIC-CNPq - UFPR. 
